\title{
Understanding Remote Presence
}

\author{
Konrad Tollmar \& Joakim Persson \\ Interactive Institute \\ Smart Things and Environments Studio \\ PO BOX 1028 \\ S-10450 Stockholm, Sweden \\ konrad@ai.mit.edu,jpe@fek.su.se
}

\begin{abstract}
In this paper, we discuss a study of new media for interpersonal communication. The paper motivates, designs and presents a small evaluation of a technology that is intended to support intimacy at distance. It first presents an ethnographic study examining family communication and the role of artifacts in supporting emotional closeness, e.g. heirlooms, activities and places in the house. The paper then describes a couple of prototypes that were designed to support different types of closeness and how we evaluated one of these prototypes in a study of 3 families (6 households), for two weeks each. The interview data that the study presents show that people were generally positive about the technology, although this depended on the nature of the users' pre-existing communication patterns. One critical point here is about the importance of pairing blue sky design with down-to-earth deployment and demonstrate commendable ethnographic-like work to inform design practice. Finally do we discuss some issues around users experiences of "telematic emotional communication" and how this has enriched our understanding of remote presence.
\end{abstract}

\section{Keywords}

Blue-sky research, interaction design, industrial design, ubiquitous computing, emotional communication, interfamily communication.

\section{INTRODUCTION}

When you enter a Scandinavian home in the wintertime you will soon realize the importance of light, and how different lamps are crucial for carrying out work and daily house chores. But the use of light is also essential to show that you are at home and to manifest the presence of life. These observations lead us to start to investigate how to use light to indicate presence. For example the act of using light to show that you are at home is something that you not only do for yourself. In many communities it is a mutual social activity with the neighbors to show that your are doing well and even that you might welcomes visits.

\section{LEAVE BLANK THE LAST $2.5 \mathrm{~cm}$ (1") OF THE LEFT COLUMN ON THE FIRST PAGE FOR THE COPYRIGHT NOTICE.}

We would like to refer to our area of research as telematic emotional communication - a type of communication media that serves multiple purposes. "Le coeur a ses raisons que la raison ne connaît pas" wrote Blaise Pascal, and emotions indeed have logic of their own. The communication of emotions appears to be largely involuntary. However, its functional complexity suggests adaptive design. Telematic emotional communication may form part of a powerful analog system of communication, including gestures and body language, which evolves alongside representational thinking.

Our hypothesis is that providing some form of continuouson and asynchronous connectivity within a meaningful social and physical context can foster better relationships and awareness among distributed family members. Existing technologies like phones already provide synchronous voice communication and to some extent asynchronous messaging. However it is not clear how these modalities are used in maintaining such relationships. A key concern for us is not to focus only on the pattern of communication within a co-residential social unit, but we were also interested in investigating what people keep in their homes to act as a reminder of people they like.

There is a big interest in HCI in the domestic domain and inter-family communication. But there are only a few examples of projects that have passed the line of turning conceptual ideas into working prototypes, and even fewer studies have gone the entire way of including the deployment of these prototypes into actual daily usages. We believe that this a very important step in this field. Hence, we suggest an approach that also includes the development of functional prototypes and makes in-depth assessment of concept design solutions possible.

\section{A Design Driven Approach}

We have found several indicators to show that a framework of design methods, which apply down-to-earth grounding and blue-sky design concurrently, could be a great support in the design of new communication media (Rogers \& Bellotti 1997). This duality reflects the way designers work, and it can be implemented in a bi-leveled understanding of a product. This has been discussed in greater length in other papers (Tollmar et al 2000), and therefore in this paper we will focus our efforts on describing the more specific outcomes in the design cycle: 
from observations to scenarios and prototype building and finally exploring daily use.

\section{Observations}

In order to base the idea of remote presence on real needs and situations, a number of observations on "real people" who represent different categories of families, representing different ages, social situations and types of living is needed. Hence a short pilot ethnographic study was undertaken in ten different households.

It is important recognize the qualitative nature of such ethnographic studies. The goal of the study was to better understand people's interpretation of their social patterns and conception of the role of communication in their relationships. In the observations the emphasis is on obtaining narratives or accounts in the person's own terms.

A series of probes (often connected to a specific question) was asked to engage the participant to discuss issues not mentioned or only slightly disclosed earlier. E.g. "You have mentioned that... Why? What does it mean for you?". As the tour went along, we hence asked questions about the different things and furniture that we passed. Questions like: "What is this?", "You did you get it from?", "What does this thing mean to you?", "Could you tell me about this rocking chair?", and so on. These focused on what things people have in their homes today, and how they use them. Our search looked for objects that either reminded people of friends and relatives or acted as a trigger for relationship maintenance.

\section{Personal Objects}

We all have our own experiences of postcards and pictures hanging on refrigerators and mirrors in our homes. This common artifacts exhibit often a link between individuals, as in this example:

"I use the mirror to place my most important pictures and postcards .. then when I use the mirror we come [for a moment] together again .. I would like to be [often] positive reminded of these person"

But the rest of the stuff that homes are filled with, what relations do we and other people have to these things? The observations showed us that all families have furnished and decorated their home with things and furniture that not only have a practical function. Many things and furniture were placed there because they reminded them of a relative, or a situation in the family member's previous life. As one women described it:

"When you where visiting grandma' you always sat in the rocking chair, she had several. It comes naturally to me to think of her when I sit in this rocking chair."

Not only objects were represented or used in this sense. One man addressed an activity to the function of relationship maintainer or reminder. He said:

"My mother likes to cook, and so do I, so eventually when I cook, I might find myself thinking, we are probably doing the same thing now, my mother and I... [...]. When I was a kid I always stood on a chair next to the stove and cooked lingonberry jam the same way mothers in my family had done for over three hundred years. And in that moment I felt connected to all the mothers..."
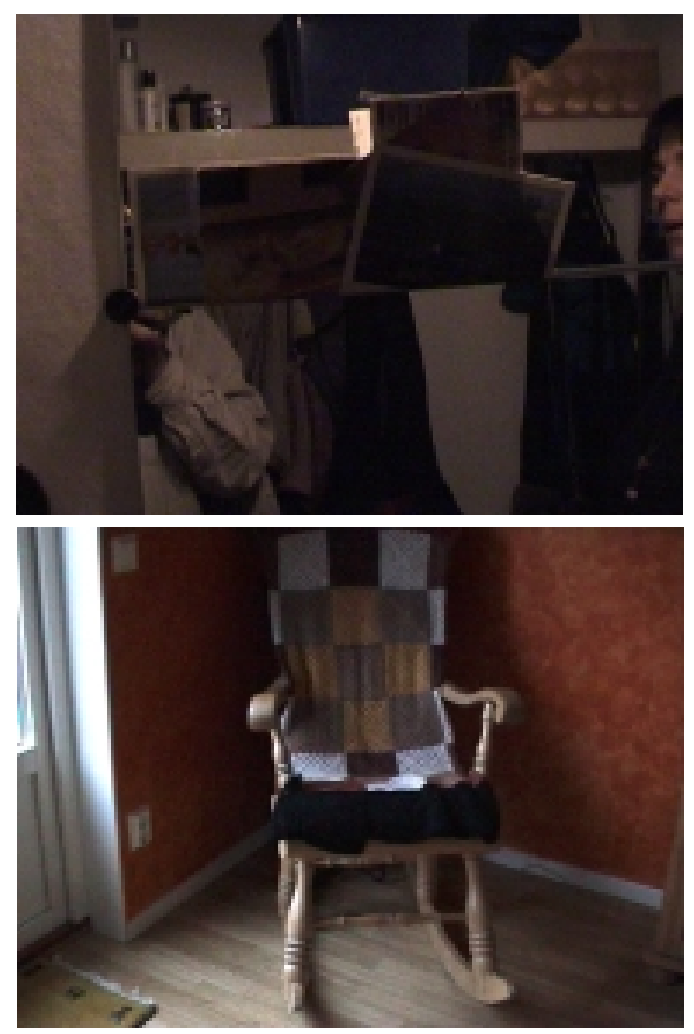

Figure 1: Objects with Personal Memories

One man claimed that the knowledge of the history of an object is important for the way he looked at the object. He said this about a table:

"I have learned to like it. I wouldn't have bought it, not even taken it for free, if it didn't mean something to me. The quality of this table lies in the knowledge of it belonging to my grandparents"

\section{Family communication}

We also observed a great need for communication within the family. Family members lived apart, some grown-up children had moved etc.

All informants were enthusiastic about email and its benefits, particularly for long-distance contact. They all claimed that they would keep in touch with folks abroad more so if they had email accessibility. However, it was not perceived to be a replacement for voice conversations, which was still considered essential for most on a regular basis. There is an anxiety if some informants not have regular voice contact; it also provides emotional support.

We were although told that telephone use usually changed when the families in our study had children. Before, they could spend hours on the phone, but now it had become a device for interchanging practical information. In many cases, they acknowledged the importance of new technology for solving daily and practical issues. However, 
being "reachable everywhere and all the time" may be problematic. One teenager reflected that he did not have deep conversations with his father on the phone, and that he wanted to know what his father was doing:

"My father always has practical excuses for calling me..."

All informants have strong links with their mothers. The mothers serves not only a parental or emotional link, but also provides news and information about others in the family. In several cases the mother was also the main initiator, some time a bit problematic as e.g. grown-up children often had a reverse feeling of guilt:

"I often feel guilty about not having enough time to call my mother"

On a related observation, all communication cannot be considered beneficial. Undesirable communication was founded to sometime be disruptive. Moreover there is some evidence that communication openness can even exacerbate family disagreement, like in this comment by a couple that lived in separate households:

"I dont like when $X$ [the partner] is just calling to complaining about our situation [living apart] .. it's so counter productive cause it often just lead to hard arguments .. in these cases I hate the phone it makes it [the situation] only worse"
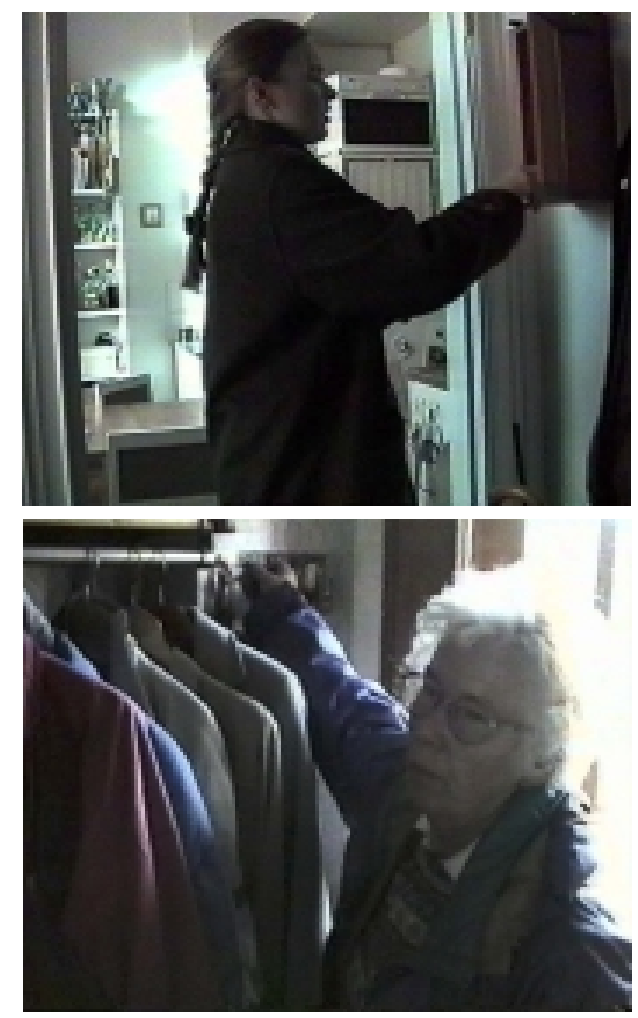

Figure 2: Observing ritual when leaving and enter home

Overall, the study has enabled us to get a better understanding of communication patterns and the use of communication technology in domestic life. We found some evidance about mixed feelings about the phone as the main media to keep in contact with friends and relatives that lived far apart. The observation did also highlight the importance of that many things and furniture that was considered to be important were placed there because they reminded them of a relative.

\section{Situation Scenarios}

As a second step, a partial scenario technique was used that we refer to as "Situation Scenarios". Actually before we started the observations, we had prepared a number of plausible scenarios that we felt were connected to the original question. The scenarios were intended to act as carriers of momentary situations, where the dynamics lie in the presence of other people, activities or media.

One of the scenarios that we asked our informants to play out involved the procedures that people performed when they left their homes, as well as when they came home. Did they have any ritual, for example handling keys, before they left or when they came home.

It was in these kinds of scenarios that we detected that the use of lights seemed to follow a common pattern which was very similar between different families. Normally, you switch off lights when you leave home, but as we found out, this is not always the case. In one case, we were told that if they just went away temporarily they usually kept the lights on to show that they where in the neighborhood. Similarly, when people entered their home they walk around the apartment to light up the place as an indicator that they are home. In this way was lights conceived to be differently compaired to other more passive objects. One man told us that:

"When I want .. or need .. to read I usally do that in our bedroom. In there [the bedroom] have I put my grandfathers old lamp. That light and the colors from the lamp remind about when I was child and he used to read for me in the evenings .. but its also tell the rest of the house that I prefer to undisturbed in my reading"

\section{Prototypes}

The next step in our design methodology is to develop ideas by thoroughly exploring the interaction while these communication artifacts are being used.

The first move was to develop a couple of industrial design models based on the key concepts captured from the observations and scenarios. Among all ideas (some more are discussed in Tollmar et al 2000) the use of light to indicate presence was the idea that we found to be most innovative and novel. We developed three different design models on this theme. It's lumicard, tree-lamp and 6th sense:

- Lumicard is a stand for postcards. Draw or write something on a postcard with an electronic tag and send it to people you care for. Keep a sensor at your home that sends awareness information to the tagged postcard. Your messages keep you connected with the Lumicard. 
- The tree-lamp is a wall mounted modular tree of lights, which enables you to map the relations between people that you care about. When you touch a certain part of the tree, the corresponding person will be notified that you have been thinking about them.

- 6th sense is a light sculpture. It uses telecommunication to respond to the remote flow of electricity, water or movement. You can place its sensors in an apartment belonging to someone close to you. By varying the intensity of the warm light from the multiple small light bulbs it becomes a living sculpture. The original idea is to build on the family tree metaphor where each leaf is a representation of a remote family member or a friend.

Based on various reasons (e.g. feedback, technology and manufacturing) we decided to proceed with developing a functional prototype from the key ideas in the $6^{\text {th }}$ sense. In the functional prototypes, the sensors and lamp are integrated into a single piece. The functional prototype consists hence of a simple one-chip computer, a couple of sensors and a GSM-modem. The GSM technology makes the $6^{\text {th }}$ sense very flexible, allowing lamps to be placed virtually anywhere.

The application was also simplified. In the current version, instead of multiple connected lamps we instead limited the concept to a pair of two lamps that are connected. Simply described, the current prototype measures the amount of body movement close to the lamp.

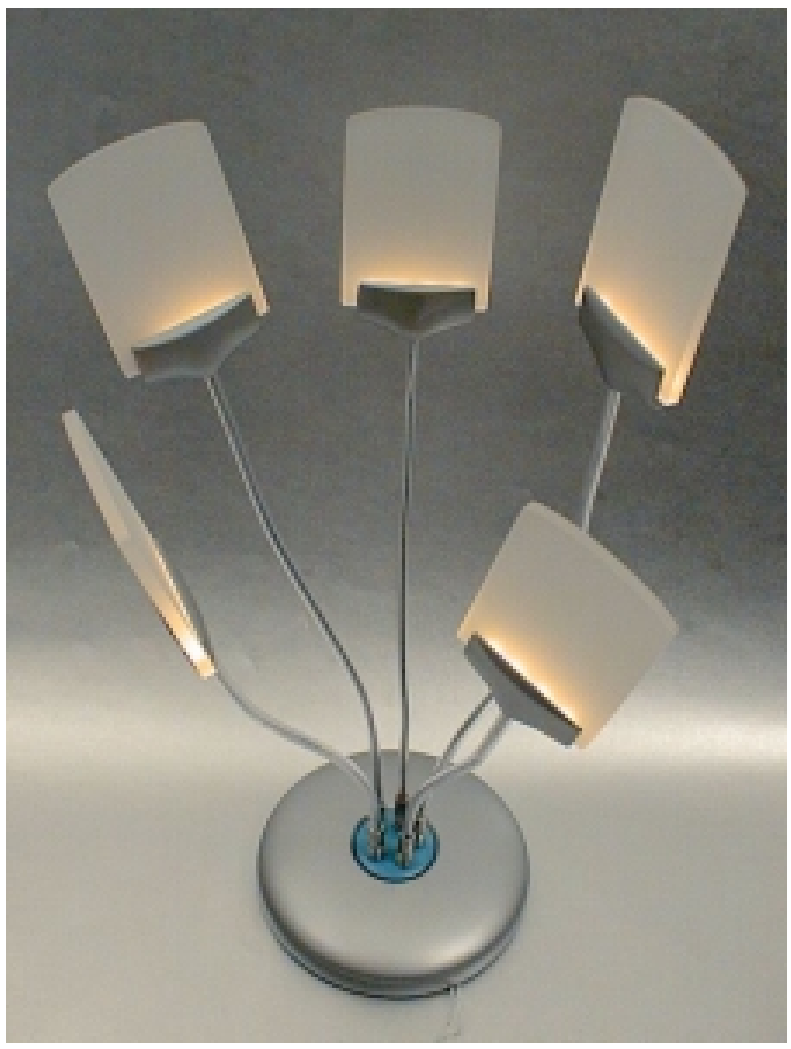

If there is continuous movement over specific time period, the lamp parses this information as presence and sends this information that then lights up on the sister lamp. The other way around, if no movement is detected then this information is also passed to the sister lamp, which then dim down.
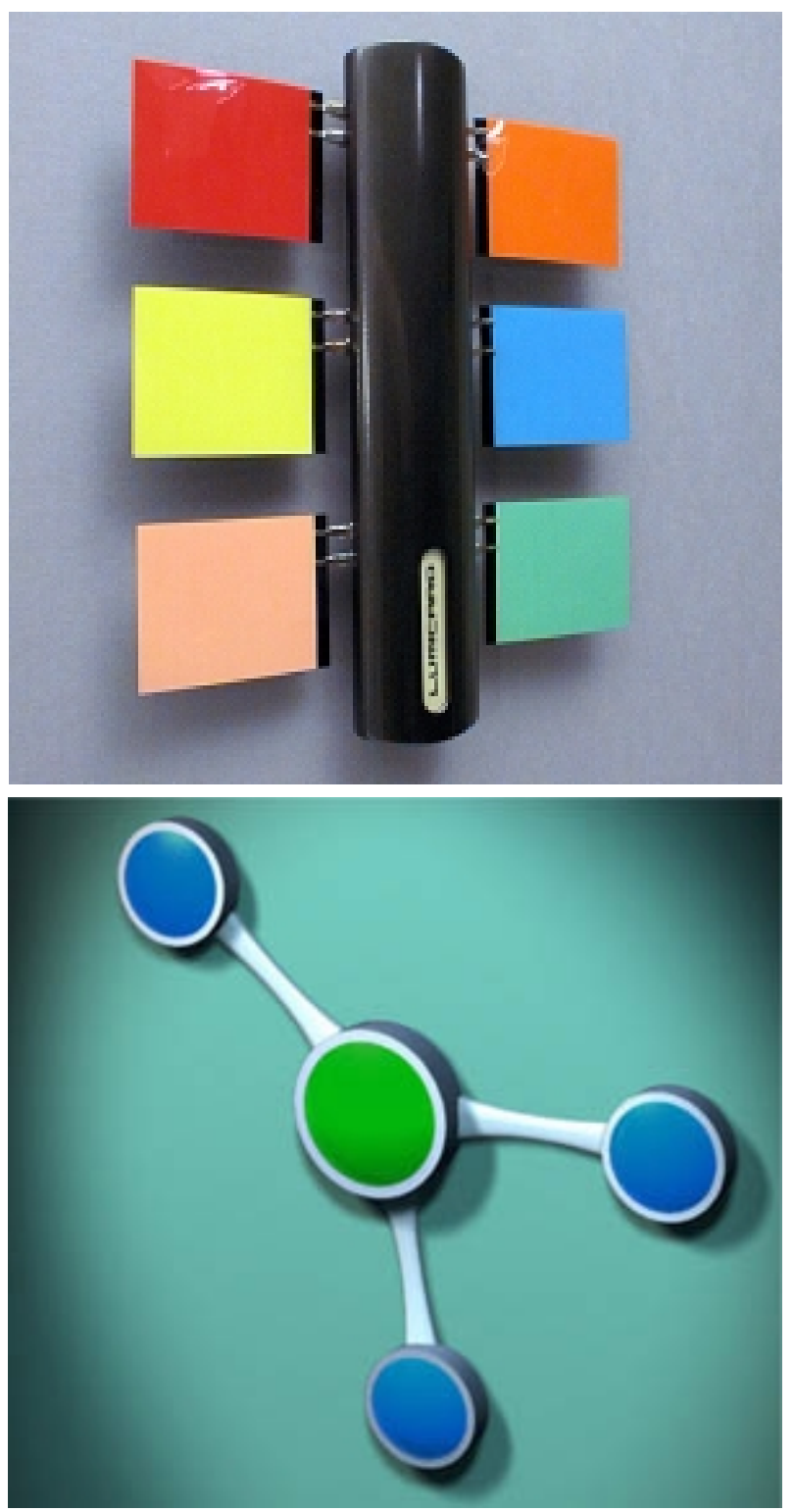

Figure 3: Industrial design protypes of $6^{\text {th }}$ Sense, LumiCard and Tree-Lamp. 


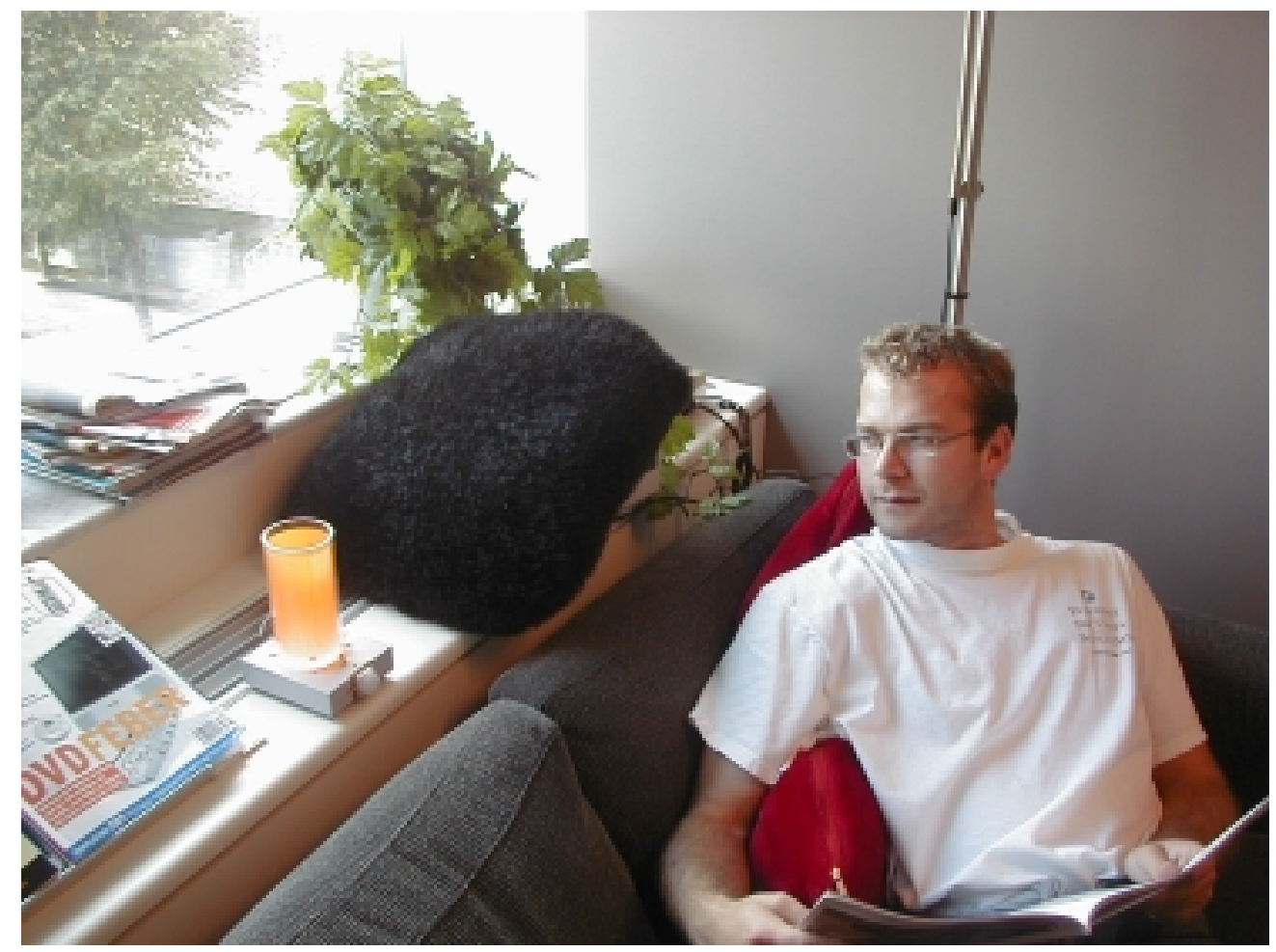

\section{Exploring daily use}

The next step was to study the actual use of these functional prototypes in daily life situations. Hence, we have been asking a couple of families to use the functional prototypes of $6^{\text {th }}$ Sense for some time in their homes. In this part of the study we would like to get deeper insights towards the use of communication modalities in maintaining relationships and pose questions regarding awareness issues, like:

- Is it possible to represent awareness information in the $6^{\text {th }}$ Sense?

- What will a person using the $6^{\text {th }}$ Sense experience?

- Could the $6^{\text {th }}$ Sense also express other types of information?

We preformed the user study in three families, each containing two households. In total were 15 persons involved in the study. In the first family, one household consisted of a married couple in their late 50's (household H1). The other household was made up of their two sons from earlier marriages (H2). In the second family, the first household consisted of a single mother, 57 year (H3), and her daughter with her family, husband and three children (H4). The third and last family consisted of a pair of siblings, each as well as their families (H5 and H6). The actual user study lasted for 10-14 days in each family.

\section{Introducing the $6^{\text {th }}$ Sense}

In introducing the study, we used several ways to help the user relate to the lamp. Firstly, we decided to use a scenario in order get the user's mindset to focus on family relations; the same way an object's own history acts like a fable for people who have a relationship to the object. We used a scenario that lead back in the old days, when people lived in small villages they could see their parent's homes by looking out their windows. If the light was lit normally, this was an indicator of that everything was fine, or normal. This scenario helped the user to relate the $6^{\text {th }}$ Sense to the remote relative by the second lamp.

As a second aid in enhancing the relations between the users of $6^{\text {th }}$ Sense, we conducted a little ritual while installing the lamps. The installation was completed in a sequence; first, we did the technical installation for the first lamp in one household and then in the other household. The two users were then asked to call each other and switch on their lamps together at the same time. They were also instructed to perform a simple function test and monitored at this time.

As a third form of help, we provided a logbook for the test situation, which the participants were asked to use as a diary to document their use and feelings about $6^{\text {th }}$ Sense. They were encouraged to write whatever they wanted in the logbook, though there were a couple of pre-formulated questions provided for every day of the test period, in order to help them get started writing.

Some of the questions were also formulated in a way that directed the writer's attention towards family relations, specifically the remote relative at the other end of $6^{\text {th }}$ Sense. These included questions like: "What do you think your brother/sister/mother/daughter is doing right now?", "What do you think they are thinking when their lamp is shining or not shining?" Other questions were formulated in a way to make the user think about the functionality of $6^{\text {th }}$ Sense. 
At the end of each day, the user was asked to write whatever he or she wanted in the diary.

\section{Introducing the $6^{\text {th }}$ Sense}

In introducing the study, we used several ways to help the user relate to the lamp. Firstly, we decided to use a scenario in order get the user's mindset to focus on family relations; the same way an object's own history acts like a fable for people who have a relationship to the object. We proposed a scenario that back in the old days, when people lived in small villages, they could see their parent's homes by looking out their windows. If the light was lit normally, this was an indicator of that everything was fine, or normal. This scenario helped the user to relate the $6^{\text {th }}$ Sense to the remote relative by the second lamp.

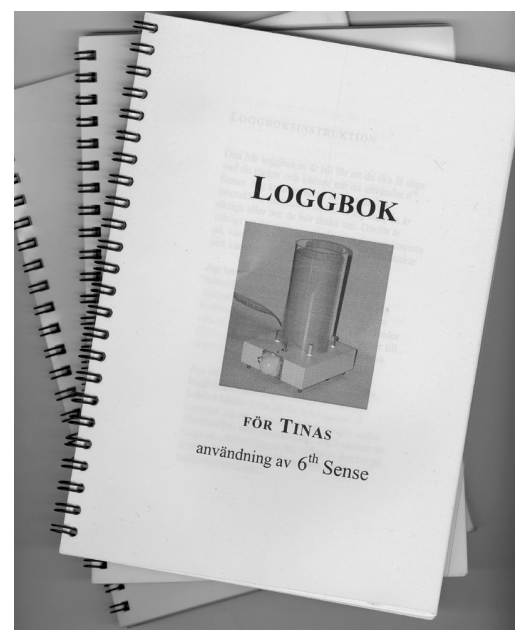

Figure 6: The logbook.

As a second aid in enhancing the relations between the users of $6^{\text {th }}$ Sense, we conducted a little ritual while installing the lamps. The installation was completed in a sequence; first, we did the technical installation for the first lamp in one household and then in the other household. The two users were then asked to call each other and switch on their lamps together at the same time. They were also instructed to perform a simple function test and monitored at this time.

As a third form of help, we provided a logbook for the test situation, which the participants were asked to use as a diary to document their use and feelings about $6^{\text {th }}$ Sense. They were encouraged to write whatever they wanted in the logbook, though there were a couple of pre-formulated questions provided for every day of the test period, in order to help them get started writing.

Some of the questions were also formulated in a way that directed the writer's attention towards family relations, specifically the remote relative at the other end of $6^{\text {th }}$ Sense. These included questions like: "What do you think your brother/sister/mother/daughter is doing right now?", "What do you think they are thinking when their lamp is shining or not shining?" Other questions were formulated in a way to make the user think about the functionality of $6^{\text {th }}$ Sense.
At the end of each day, the user was asked to write whatever he or she wanted in the diary.

Users reactions

After each family had been using the lamp for about two weeks, we went back and conducted brief interviews with the families. Together with the logbooks, we were able to formulate an understanding of how they have experienced the $6^{\text {th }}$ Sense. We categorized these results in two different ways: sense of presence and sense of surveillance. The first category is a way to understand or express feelings of relations and togetherness with the remote relative. The second category tried to understand the feeling of being watched and monitored.

Examples of findings in the first category can be a mother (H1) saying:

"The lamp really reminds me of my two sons. It feels as they are here."

Another mother (H3) said:

"The information that I get from the lamp makes me feel that I'm part of my daughter's life."

Her daughter continued:

"You think a lot of about other person. More thoughts than usual. You see pictures, what she is doing, how she moves in the rooms etc. Often you have thoughts that are more direct, ask questions in a more direct matter and so on. Now you think more like, well, now is she awake, at home she's doing something, what is she doing right now... It feels good, in a way, the need for telephone contact isn't so big as it usually is. I can see that she comes and goes, and then I know that everything is OK, if not she would probably give me a call."

The father in $\mathrm{H} 1$ had a slightly different way of looking at the lamp and the telephone. He said:

"The lamp would probably mean more to me if I didn't have so much contact with the two boys over the phone"

And he continued later with:

"I think the lamp will work better when you don't have so much telephone contact as I have with my son."

For him the lamp obviously did not contribute any enhanced sense of contact, since he had so much contact already over the telephone. A way to understand this is that he said in the interview that his contact with the boys was more of a practical nature, e.g. deciding where and when to meet and so on. The daughter in $\mathrm{H} 4$ and her mother H3, on the other hand, have the habit of talking with each other over the phone a couple of times each day. Many of these phone calls have the purpose of feeling connected, to experience a feeling of togetherness. With the lamp present they did not feel the need to call each other more than every second day or so. But the experience of the other person was even stronger than the telephone contact had given them before. 
When it comes to the category of sense of surveillance, it was only the parents who expressed that they were worried about that. The mother in $\mathrm{H} 1$ said:

"I think it is important that we don't give the two boys a feeling of surveillance or that we suddenly become too present."

The boys (H2) on the other hand, claimed that if that feeling ever occurred, they could easily turn the lamp off, but they had not experienced anything like a feeling of surveillance thus far.

\section{THE ANTHROPOLOGY OF FAMILY COMMUNICATION}

The literature in social anthropology have informs us about the complex notions of family and household and patterns of domestic interaction. However, to understand and enhance domestic communication and awareness, we must consider how people maintain social relationships in home and work life, and the role of technology in these settings. There is much to be gained by closely examining the literature in sociology and social anthropology in regards to domestic life and communication patterns within the family. We look primarily towards social anthropology rather than studies in communication psychology as we are more concerned with human interaction with other individuals (through devices in some cases), rather their conceptions of self and interactions with the devices themselves.

Family communication can be broadly concerned with behavior such as exchange, power (influencing behavior, exchanging resources), task assignment, and expression of affection or disapproval (Aldous 1982) as well as nondirected given-off impressions (Goffman 1961). An important concern is how does one evaluate impact or benefit of such communication processes. It is clear that the quantity of transactions is not as important as the quality of the interaction. On a related note, it must be observed that all communication cannot be considered beneficial. Undesirable communication can be disruptive. Moreover there is some evidence that communication openness can even exacerbate marital disagreement, especially when it reveals irreconcilable differences (Aldous 1982).

Overall this again points to the fact that even in conflict resolution the quality of communication rather then quantity seems to be important. Another important dimension pointed out by Neidhart considers "system transparency" in family interaction (Neidhart 1976). This reflects one's knowledge of other's needs and satisfactions; a form of social awareness leading to reciprocity in behavior.

This kind of early work has inspired and invoked a general interest of research in HCI in the domestic domain. The Presence project (Gaver 1999) used cultural probes to consider design for communication in elderly communities. British Telecom has done a number of larger-scale field experiments that consider the role of monitoring and communication devices in homes (Barnes 1998).
Recent projects have undertaken the design of smart homes as test-beds for new technologies, such as the Aware-Home at Georgia Tech (Kidd et al 1999) and the House_n project at MIT (Intille et al 2000). However, it is not clear that a smart home support the cognitive demands and social relationships critical in domestic life. The ComeHome project at KTH / II (Junestrand et al 1999) take here a bit different approach by focusing on communication however the ComeHome appartement is still to be considered lab where most ideas is several year ahead before being put into actual use.

Other promising design approach can be found in the Philip's project "Vision of the Future". Devices for emotional communication in the latter project are attractive on two levels; as objects in their own right, as they are made of rich material to last and be cherished, and as carries of messages of special significant (Philips 1997).

Brave and Dahley (1997) have, for instance, proposed to examine the potential of touch for use as a mood-induction technique for emotional communication. Other visionary examples that steam from a mixture of art and humancomputer interaction are proposed by, e.g., Gaver \& Martin (2000) and Ishii \& Ullmer (1997). The Digital Family Portraits project at Georgia Tech (Mynatt et al 2001) examine also the use of a day-to-day awareness is key to providing peace of mind for family members. Similar has the Casablanca project studied different forms of household communicators but again - there are only a few examples of projects that have passed the line of turning conceptual ideas into working prototypes, and even fewer studies have gone the entire way of including the deployment of these prototypes into actual daily usages.

\section{DISCUSSION}

The general responses from our user study were basically in the line with what we expected. We have tried to create a synthetic relation expression between two households in a family, where there already was an active communication string. What did surprise us were the overwhelming positive reactions that people raised in the study.

The criteria we found to be crucial for developing an artifact that could function as a representation of remote presence is the relation itself. Every object that was mentioned with some kind of affection in people's homes had its own history for its owner. The objects that only served utilitarian purposes were not mentioned spontaneously at all, i.e. we had to ask about them.

These findings made us think that if people do not have a relation with $6^{\text {th }}$ Sense, or if the connection between the two users of the lamp is not obvious, the light from $6^{\text {th }}$ Sense may mean nothing to the users. So why did the light of $6^{\text {th }}$ Sense work that well as a representation of someone's presence in their home, and a lack of light as an indication that the person(s) is not there?

One common reaction towards the $6^{\text {th }}$ Sense was that the warm light gave them a feeling of security and did not 
include at all a feeling of surveillance that we were worried about. Even if our observations focus on how families use light, another level of meaning that is ascribed to the use of light. A daughter in the study confirmed that, "I can see that she comes and goes ... and then I know that everything is OK, if not she would probably give me a call." This journal data is a key indicator that the meaning and importance of light (in this instance) or awareness (in general) serves different end oals. Here, light and/or presence may also indicate safety or security. Other participants construed different meaning from light/presence, like the comments that it acted as a reminder of the porch light in one family summerhouse (H1),

"The lamp reminds us about the porch light .. Its warm and welcome .. it also remind us about a nice times that we have out there .. hence the lamp soon become a close friend"

Secondly, the non-intrusive property was an important factor in how well the $6^{\text {th }}$ sense was perceived - after all, it was just a lamp that could be turned off if desired.

As mentioned above, one family decreased their use of the telephone between the households in the family. This change in behavior is an interesting detail in the study that raises a lot of questions. We would like to argue that a communication media that could carry this kind of richness will also be much better at establishing a relationship to the person that the communication artifact is connected to. Other examples could be to explore the possibility of communicating body heat, or ambient sounds.

What make this study still preliminary are two important factors. In forthcoming studies we would like to extend the time for the field study. So far time is mostly an unknown factor in this study. For instance, what will happen when people have the device for such a long time that they almost forget about it; when it becomes a natural part of one's home? Secondly even with our best effort did we have some technical problem with the functional prototypes. This made it difficult for the families to, e.g., freely move around the lamp (although in practice this was never asked) and to be able to master the lamp as any kind of household appliance. We still have a long way to go before this kind artifacts could become transparent in its use and act as the ambient source of communications as we strive towards.

\section{ACKNOWLEDGMENTS}

We would like to gratefully thank all the people that contributed to this work; Lennart Andersson, Jakob Boije, Aurilian Brie and Cristi Bodgan. We would also like to express our gratitude to Prof. Yngve Sundblad, director of the Center for User-Oriented IT-design at the Swedish Royal Institute of Technology, and Ingvar Sjöberg, director of the Smart Things and Environments for Art and Daily Life Group at the Interactive Institute, for their support throughout the project. The Emotional Communication research project was conducted at the Smart Studio at the Interactive Institute in Sweden.

\section{AUTHORS ADRESSES}

Joakim Persson, Stockholm University, School of Business, SE - 10691 Stockholm, Sweden.

Konrad Tollmar, MIT - AI Lab, NE43-836, 200 Tech Square, Cambridge, MA02139, USA.

\section{REFERENCES}

1. Brave S. \& Dahley A., inTouch: A Medium for Haptic Interpersonal Communication, In Proceedings of $\mathrm{CHI}$ '97, ACM Press, 1997.

2. O'Brien J. \& Rodden T., Interactive systems in domestic environments, In Proc. Of DIS '97 : Designing interactive systems: processes, practices, methods, and techniques, ACM Press, 1997.

3. Dunne A. \& Raby F., Fields and Thresholds, Doors of perception-2, www.mediamatic.nl/doors/Doors2/DunRab, 1997.

4. Ekman P., An Argument for Basic Emotions, Cognition and Emotion, 6 (3/4) pp. 169-200, 1992.

5. Gaver, B., Dunne, T., Pacenti, E. 1999. Cultural Probes. ACM Interactions. Jun-Feb 1999.

6. Gaver B. \& Martin H., Alternatives: Exploring Information Appliances Through Conceptual Design Proposals, In Proc. of CHI'2000, Den Haag, ACM Press, 2000.

7. Gaelick L., et al ., Emotional Communication in Close Relationships, Journal of Personality and Social Psychology, Vol. 49, pp. 1246-1265,1985.

8. Harasim, L. (ed.), Global Networks: Computers and International Communication, MIT Press, 1993.

9. Hollan J. and Stornetta S., Beyond Being There, In Proc. of CHI92, ACM Press,1992.

10. Intille, Stephen, Larson, Kent, Kukla, Charles, et al. 2000. House_n: The MIT Home of the Future Project. MIT Dept. of Architecture. http://architecture.mit.edu/house_n/

11. Kidd, Cory D., Robert J. Orr, Gregory D. Abowd, Christopher G. Atkeson, Irfan A. Essa, Blair MacIntyre, Elizabeth Mynatt, Thad E. Starner and Wendy Newstetter. 1999. The Aware Home: A Living Laboratory for Ubiquitous Computing Research. In the Proceedings of the Second International Workshop on Cooperative Buildings - CoBuild'99. Position paper.

12. Debby H., Mainwaring S., Leduc N., Hagström A., Bayley O.: Casablanca, In Proc of CHI 2001.

13. Ishii, H., and Ullmer, B. Tangible Bits: Towards Seamless Interfaces Between People, Bits and Atoms. In Proc. of CHI '97, ACM Press, 1997.

14.Junestrand S. \& Tollmar K., The Dwelling as a Place for Work, in Cooperative Buildings - Integrating Information, Organization, and Architecture. Proc. of CoBuild'98, Streitz, N., Konomi, S., Burkhardt, H.-J. (Eds.), Springer: Heidelberg, 1998. 
15. Mynatt E, Rown J., Craighill S., Jacobs A: Digital family portraits: supporting peace of mind for extended family members. In Proc of CHI 2001: 333-340

16. Philips, Vision of the Future, V+K Publisher, Holland, 1997. Also at http://www.philips.nl/design/vof

17. Picard R., Affective Computing, MIT Press, 1997.

18. Netherlands Design Institute, Presence: New Media for Older People, I3Net, www.I3Net.org or www.presenceweb.org, 1999.

19. Philips, Vision of the Future, V+K Publisher, Holland, 1997. Also at http://www.philips.nl/design/vof
20.Rogers, Y. and Bellotti, V, Grounding Blue-Sky Research: How Can Ethnography Help?, ACM Interactions 4(3), 1997.

21.Strong, R., \& Gaver, B. Feather, Scent and Shaker: Supporting Simple Intimacy. Proceedings of CSCW '96, ACM Press, 1996.

22. Tollmar, K., Junestrand S. and Torgny O., Virtually Living Together - A Design Framework for New Communication Media, In Proc. Of DIS '2000 : Designing interactive systems: processes, practices, methods, and techniques, ACM Press, 2000. 